\title{
OFICINA DE REESCRITA E CRÍTICA LITERÁRIA EM ATO NA UNIVERSIDADE 1,2,3
}

\author{
Violaine Houdart-Merot ${ }^{*}$
}

RESUMO: Tradução para o português do artigo "Atelier de réécriture et critique littéraire en acte à l'université", de Violaine Houdart-Merot, publicado originalmente no Journal français de psychiatrie, v. 31, n. 4, 2007. Neste trabalho, a autora faz um balanço de suas experiências enquanto ministrante de uma oficina de "Escrita de invenção e reescrita" para os alunos de graduação da Université de CergyPontoise, com foco no estudo da intertextualidade. Além da apresentação dos objetivos e do funcionamento da oficina, a autora propõe uma reflexão sobre os pressupostos teórico-metodológicos que a embasaram e sobre as potencialidades dessa modalidade de ensino de literatura via atividades de criação literária.

PALAVRAS-CHAVE: Ensino de literatura; Ensino universitário; Intertextualidade; Oficina de criação.

\footnotetext{
${ }^{1}$ Tradução para o português do artigo "Atelier de réécriture et critique littéraire en acte à l'université", de Violaine Houdart-Merot, publicado originalmente no Journal français de psychiatrie, v. 31, n. 4, p. 39-43, 2007.

2 Tradutor: Diego Grando. Professor colaborador do Programa de Pós-Graduação em Letras da Pontifícia Universidade Católica do Rio Grande do Sul (Puc-RS), bolsista de pós-doutorado (PNPD/Capes). Doutor em Letras (Estudos de Literatura) pela Universidade Federal do Rio Grande do Sul (UFRGS).

${ }^{3}$ As citações e referências feitas ao longo do artigo, sempre que disponíveis em língua portuguesa, foram substituídas pelas traduções e edições correspondentes.

* Professora emérita de Literatura Francesa na Université de Cergy-Pontoise, coordenadora do eixo Créations do centro de pesquisa $A G O R A$, voltado ao estudo dos processos e teorias da criação. Suas pesquisas giram em torno da cultura literária e sua transmissão, dos processos de criação literária e das literaturas francesa e francófonas contemporâneas.
} 
Em um contexto de crise dos estudos literários, no qual nos inquietamos pelo desinteresse e pelo insucesso dos estudantes de Letras, parece cada vez mais urgente repensarmos o lugar ocupado pela escrita. A pouca importância dada aos trabalhos escritos (mesmo metatextuais) e a ausência de uma escrita de dimensão literária em uma disciplina que se pretende artística explicam, em boa medida, as desistências em cursos de graduação e a dificuldade de boa parte dos estudantes que iniciam um mestrado em levar a cabo seus trabalhos de pesquisa. Reforçar o papel da escrita, e de modo mais geral, da expressão, seja ela escrita ou oral, não mais relegá-la apenas à escrita crítica, poderia ser um dos meios de voltar a dar sentido a esses estudos e, indiretamente, de possibilitar aos estudantes um melhor domínio também no âmbito da escrita crítica.

Partiremos da análise de uma prática de escrita realizada já há seis anos na Universidade de Cergy-Pontoise junto a estudantes de terceiro ano de graduação em Letras ${ }^{4}$. Trata-se de uma oficina de escrita, atualmente opcional, exclusivamente centrada em procedimentos intertextuais, comportando uma significativa dimensão reflexiva e teórica. A oficina compreende doze encontros de três horas, ao longo dos quais momentos de escrita individual alternam-se com momentos de leitura em voz alta (abrindo espaço a análises e sugestões de correções), com intervalos teóricos situados às vezes no início, às vezes no final da aula. Para cada proposta de escrita é solicitada uma segunda versão (retomada da primeira ou versão nova), geralmente produzida fora de sala de aula, a partir das sugestões dadas tanto pela professora quanto pelos outros estudantes, que assumem um papel de comitê de leitura.

Os encontros são concebidos segundo uma exigência dupla, a de abordar os principais gêneros literários (conto, novela, poesia, monólogo e diálogo teatral, formas breves como a máxima etc.) e também as principais relações intertextuais ${ }^{5}$, das mais recorrentes às

\footnotetext{
${ }^{4}$ Essa experiência dá seguimento à publicação de uma obra de caráter tanto teórico quanto prático, destinada a secundaristas mas também a estudantes de Letras, Réécriture et écriture d'invention au lycée (2004).

${ }^{5}$ No sentido em que Julia Kristeva introduz a noção em Introdução à semanálise, sentido em seguida retomado por Laurent Jenny, Michael Riffaterre ou Pierre-Marc de Biasi.
} 
mais ocultas, desde a citação ou o centão ${ }^{6}$ até as relações arquitextuais, passando pelos múltiplos procedimentos intertextuais, tais como a tradução, a adaptação, a transposição, a paródia, o travestimento burlesco, os pastiches de autores, de movimentos literários e de gêneros ${ }^{7}$. A intertextualidade é abordada, portanto, ao mesmo tempo como ferramenta de leitura e de escrita.

Essa oficina, intitulada "Escrita de invenção e reescrita" (Écriture d'invention et réécriture), dá lugar a uma avaliação dupla: primeiro, a entrega de um dossiê com o conjunto das produções feitas durante os encontros, assim como as novas versões redigidas fora de sala de aula; depois, os comentários críticos individuais sobre essas produções, podendo integrar reflexões sobre os trabalhos dos outros estudantes ou sobre os procedimentos propostos. Além desse relatório (equivalente a um trabalho feito em casa), há um trabalho feito em sala de aula, ao final do semestre. Trata-se de uma espécie de ensaio, balanço pessoal, de uma reflexão sobre a literatura e sobre o lugar da intertextualidade nos processos de escrita, calcada na experiência da oficina, nos textos literários trabalhados ao longo das aulas e nos diversos aportes teóricos.

Essas aulas de escrita pretendem, portanto, atingir diversos objetivos, mas chegam inadvertidamente a outros, que não estavam previstos a priori e mostraram-se essenciais. Foram as próprias análises dos estudantes que revelaram a importância desses efeitos inesperados.

\section{Diversificar a escrita, facilitar o acesso à escrita}

O principal objetivo é, primeiro, assim como para um grande número de oficinas de escrita ${ }^{8}$, explorar a escrita literária e facilitar o acesso à escrita através dos dispositivos postos em prática: propostas elaboradas de acordo com um desenvolvimento progressivo,

\footnotetext{
${ }^{6}$ Poema feito a partir da colagem de versos de outros poemas, de um ou mais autores. [N. T.]

7 Sobre a noção de pastiche de gênero, ver meu artigo "Le pastiche de genre, entre feinte et réflexivité" (2006).

${ }^{8}$ Ver, por exemplo, a obra já antiga, mas sempre atual, de Alain André, Babel heureuse (1989).
} 
mais orientado nas primeiras aulas; restrições (contraintes) que libertam a escrita; estímulo devido à escrita em grupo e ao tempo limitado; orientação e ajuda do professor; leitura em voz alta do texto escrito (com a possibilidade de eventualmente não fazê-lo, já que a leitura diante dos colegas pode ser uma obrigação intimidadora em um primeiro momento, mas bastante benéfica ao final).

Deixaremos de lado o interesse, para quem quer que seja, de ter acesso a uma escrita pessoal e criativa, independentemente de qualquer projeto profissional.

Também passaremos rapidamente sobre a importância, para os estudantes de Letras, de entrar em contato com a escrita literária, em toda a sua diversidade, de adquirir assim um maior domínio da expressão escrita, uma maior desenvoltura, um maior prazer, sabendo que muitos deles, em suas vidas profissionais, serão confrontados com modos de escrita muito mais diversificados que apenas a escrita de comentários críticos, quer eles se orientem em seguida para uma carreira jornalística, quer para as áreas do livro, da comunicação, do turismo ou da edição - sem falar do ensino, se considerarmos a necessidade de se ter uma experiência pessoal de escrita para poder ensinar a escrever, e ensinar a escrever todos os tipos de textos.

Mas esse treinamento para a escrita literária, tal qual é concebido aqui, tem a ambição comum de fazer não só, segundo a fórmula de Marcel Proust a respeitos dos pastiches de escritores", "crítica literária em ato”, mas também teoria literária e história literária em ato, por intermédio da própria escrita. Dito de outro modo, a oficina de escrita baseada nos textos literários, concebida como oficina de reescrita, e integrando uma parte de reflexividade, permite, ao cabo, que se encontre a escrita crítica, com certos desvios, mas com uma eficácia às vezes muito mais forte. Com a condição, no entanto, de zelar por certos princípios que podem ser resumidos em três palavras: intertextualidade, reflexividade e reelaboração das primeiras versões.

\footnotetext{
${ }^{9}$ Mas, como veremos, esta oficina não se reduz aos pastiches de escritores; as outras formas de hipertextualidade igualmente permitem que se faça crítica literária em ato.
} 


\section{Descobrir os paradoxos da escrita literária}

Abordar a escrita através da intertextualidade é uma maneira de tornar visível um processo de escrita fundamental, mas que nem sempre é consciente, que "todo texto se constrói como mosaico de citações" (KRISTEVA, 1974, p. 64), e que escrevemos sempre a partir dos escritos dos outros, inclusive quando não se trata de processos de reescrita que se mostram como tal. Assim, as relações de ordem taxinômica que uma obra estabelece com os gêneros ou subgêneros também se incluem na intertextualidade, tal como definem Julia Kristeva ou Laurent Jenny ${ }^{10}$, e tornar evidentes essas relações habitualmente ocultas exerce um papel tanto para a escrita quanto para a leitura.

Desse modo, de acordo com um paradoxo inerente à literatura, apercebemo-nos que a originalidade não é dissociável da imitação, concebida como apropriação e transformação ou transgressão de textos, de discursos ou de gêneros existentes (e não como simples aplicação de regras, forma a que frequentemente temos tendência a reduzir a imitação). Pelo contrário, a imitação consciente e deliberada pode se tornar uma forma de exorcismo ${ }^{11}$ contra a imitação inconsciente e não controlada. Mais precisamente, trata-se, nesta oficina de "escrita intertextual", de propor aos estudantes trabalhos de escrita que se inspirem em procedimentos intertextuais já postos em prática por escritores: por exemplo, inserir em

\footnotetext{
${ }^{10}$ Ver Laurent Jenny (1979, p. 5): "Fora da intertextualidade, a obra literária seria muito simplesmente incompreensível, tal como a palavra duma língua desconhecida. De facto, só se apreende o sentido e a estrutura duma obra literária se a relacionarmos com os seus arquétipos - por sua vez abstraídos de longas séries de textos, de que constituem, por assim dizer, a constante".

${ }^{11}$ Ver Marcel Proust (1994, p. 77): “[...] eu não poderia deixar de recomendar aos escritores a virtude purgativa, exorcizante, do pasticho. Quando se acaba de terminar um livro, não somente desejar-se-ia continuar a viver com seus personagens, com a sra. de Beauséant, com Frédéric Moreau, mas, além disso, nossa voz interior, instruída que foi durante todo o tempo da leitura a seguir o ritmo de um Balzac, de um Flaubert, desejaria continuar a falar como eles. É preciso deixá-la agir por um momento, deixar o pedal prolongar o som, isto é, fazer um pasticho voluntário, para poder, depois disso, voltar a ser original, e não fazer durante toda a vida um pasticho involuntário".
} 
seu texto uma citação desviando-a de seu sentido original (como faz Molière ao retomar um ou outro verso de Corneille); ou então fazer uma personagem falar, no teatro ou em um romance, pastichando tal ou tal discurso social ou literário: fala camponesa (Maupassant), discurso patriótico (Céline) ou estereótipos românticos (Flaubert); inspirar-se no dilema corneliano para escrever uma paródia de monólogo de teatro (Tardieu); fazer um travestimento burlesco da descida de Ulisses ao inferno na Odisseia de Homero, como o fez Rabelais em seu Pantagruel. Ou, finalmente, partir do "Dormente acordado" das Mil e uma noites, de sua reescrita oblíqua por Proust no início da Recherche ${ }^{12}$, para escrever sobre o estado de dormente acordado próprio ao momento do despertar. Ao fazermos isso, tomamos consciência de que a interpretação de um texto literário se apoia quase sempre em uma leitura intertextual: como interpretar a descida de Epistemon ao inferno, em Rabelais, se não identificarmos sua dimensão paródica e carnavalesca e a pluralidade de leituras que daí derivam? Ou seja, fazer um estudante escrever propondo-lhe que explore um processo intertextual é uma maneira de fazê-lo compreender do interior, através de uma experiência de escrita, a ligação entre intertextualidade e interpretação, entre intertextualidade e literariedade de uma obra.

A outra experiência que os estudantes têm ao praticarem a “imitação" e escreverem a partir dos escritos de outros é a da diversidade surpreendente das produções e de sua dimensão fortemente pessoal e implicada, mesmo que as propostas não os levassem a priori a falar de si próprios, fosse a escrita de um perfil à maneira de Céline ou de La Bruyère, ou a reescrita do mito de Pigmalião ou do mito de Babel, efetuando-se mudanças espaçotemporais ou axiológicas, ou, ainda, escrever um monólogo de teatro a partir de um poema de Tardieu. Dito de outro modo, a restrição (contrainte), por um aparente paradoxo, liberta e torna possível a expressão de si. Os estudantes, assim, tomam consciência, por dentro, através dessa experiência de escrita coletiva, do fato de que a expressão pessoal se acomoda perfeitamente bem, inclusive precisa, às vezes, de desvios.

${ }^{12}$ Sobre isso, ver meu estudo sobre "Proust Dormeur éveillé ou comment surseoir à l'arrêt de mort" (2005b). 
Enfim, cada um pode constatar durante as aulas de escrita coletiva o quanto a escrita pode conduzir a direções completamente inesperadas. Isso vale tanto para a escrita criativa quanto para qualquer forma de elaboração intelectual. A análise de Clément Rosset (1995, p. 29) é certamente aplicável a qualquer forma de escrita: "Só existe pensamento a partir do momento em que aquilo se formula, isto é, se constitui pela realidade das palavras".

Assim, ao escrever um poema a partir da reprodução de uma obra pictórica, uma estudante surpreendeu-se ao abordar a questão, por muito tempo dolorosa para ela, da cor de sua pele e da dificuldade precisamente de falar sobre. Uma outra viu surgir a figura de um avô morto por meio de uma carta a um desconhecido. O desvio da restrição (contrainte) torna possível a confissão de segredos, precisamente porque essa confissão permanece indireta e discreta. Trata-se de uma descoberta essencial, a da primazia e do poder das palavras: “as palavras que vão surgir sabem de nós o que nós ignoramos delas” (CHAR, 1983, p. 534). O trabalho sobre o centão é particularmente revelador disso. Quando, a partir de um mesmo conjunto de poemas em alexandrinos, os estudantes elaboram o próprio poema, feito da colagem de hemistíquios, constatam por si próprios que produzem poemas de uma diversidade surpreendente, dos quais é possível identificar cada autor, tanto os centões se parecem com eles.

\section{Fazer história literária em ato}

$\mathrm{Na}$ medida em que explora uma diversidade de processos intertextuais, essa oficina de escrita também permite que se faça história literária em ato, a partir de uma nova abordagem da história literária. Com efeito, o fato de apreender o texto literário como uma produtividade ${ }^{13} \mathrm{em}$ que intervêm menos as relações entre o texto e o real (e, por consequência, a História) que entre este texto e os outros textos que ele absorve, que ele transforma ou com os quais ele entra em diálogo, leva a reintroduzir a história literária, posta

\footnotetext{
${ }^{13}$ Ver Roland Barthes (2004, p. 275-276): “[...] todo texto é um intertexto; [...] é toda linguagem, anterior e contemporânea, que vem para o texto, não pelo caminho de uma filiação detectável, de uma imitação voluntária, mas segundo o caminho da disseminação - imagem que garante ao texto status de produtividade, não de reprodução".
} 
em causa pela crítica formalista e pela perspectiva do texto encerrado sobre si mesmo. A história literária, concebida dessa maneira, sofre então um deslocamento: do contexto histórico para a história das formas e das ideias. Como explica Sophie Rabau (2002, p. 33), a intertextualidade supõe, com efeito, "um deslocamento na própria concepção de interpretação literária": onde se interpretava o texto em função de causas exteriores, segundo um eixo lógico-temporal, "será preciso interpretá-lo em função de uma rede onde ele se emaranha”.

Por essa ótica, podemos definir a história literária como história das operações pelas quais os textos reescrevem outros textos e os gêneros engendram outros gêneros, em um movimento que é ao mesmo tempo de interpretação, de imitação transformadora e de transgressões incessantes. Os textos literários são então apreendidos não somente como signos e discursos sobre a história (e não simples produtos da história, como era o caso em uma concepção tradicional da história literária), mas também como reescritas (ou releituras) dos textos que os precederam ou que estão à sua volta. Tal abordagem da história literária, que não esvazia os textos, mas se apoia neles, dá acesso à historicidade das obras, sem com isso escamotear a dimensão interpretativa. Ela permite igualmente reintroduzir o leitor, uma vez que o texto é concebido como produtividade na qual o receptor tem um papel a cumprir para a elaboração do sentido e o acesso à significação.

Esta história literária em ato, posta no centro da oficina de escrita, pode se ramificar em diversas direções, especialmente a da história das ideias, dos movimentos literários e dos gêneros. Não nos ateremos sobre a história das ideias, relativamente fácil de identificar através das reescritas de mitos ou de lendas: a confrontação de diversas versões de uma mesma história permite que se veja como cada retomada é uma reinterpretação reveladora dos valores e das ideologias de uma época: assim, o herói epônimo do Édipo de Corneille, surpreendentemente cristão e defensor do livre-arbítrio, é muito diferente do Édipo Rei de Sófocles ou do Édipo de Sêneca. Também a reescrita de La Fontaine da história dos amores de Psiquê e de Cupido é reveladora de uma visão epicurista (ou mesmo libertina) que não existia na versão de Apuleio. Se compararmos o desenlace do conto de La Fontaine a seu 
hipotexto apuleico, vemos claramente que o hino à Volúpia, criança nascida dos amores de Cupido e Psiquê, tornada imortal depois de ter sido perseguida pelo ciúme de Vênus, entrelaça diversos hipotextos, sendo o mais significativo, aqui, o hino a Vênus de Lucrécio em De natura rerum. As semelhanças são muitas: solenidade, forma versificada, apóstrofe a Volúpia-Vênus, escrita do elogio, tema do amante universal e, consequentemente, do desejo como motor da vida e, por trás disso, principalmente, concepção antimetafísica do mundo: a felicidade aparece como ao alcance do homem. Mas a volúpia aparece aqui também como musa inspiradora do poeta (com em Lucrécio, que abre seu longo poema com este hino): o prazer é concebido, inclusive, como critério estético. Seu conto termina no elogio do "mais belo espírito da Grécia" e na tomada de posição ao mesmo tempo epicurista e poética. Aí se vê o quanto a leitura intertextual nutre a interpretação do conto.

Um trabalho de escrita pode possibilitar que se tornem mais tangíveis esses diálogos intelectuais entre épocas e os efeitos de entrelaçamento de diversos hipotextos. Trata-se, por exemplo, de reescrever uma fábula de Esopo dando a ela uma dimensão epicurista (com o acréscimo de textos epicuristas, tais como a famosa carta de Epicuro a Meneceu sobre a morte, ou então o hino a Vênus de Lucrécio em De natura rerum).

\section{Reescrita e história dos gêneros}

A história dos gêneros deriva igualmente de mecanismos intertextuais em sentido amplo. Podemos considerar, por exemplo, que o nascimento da tragédia grega é fundamentalmente intertextual: a maioria das tragédias gregas do século V a. C. são, na verdade, amplificações de passagens de epopeias que fazem alusão a um ou outro mito. Édipo Rei tem como hipotexto alguns versos homéricos e se apresenta como a transposição de uma narrativa em diálogo teatral, em outras palavras, a transformação de uma "mimese direta", segundo os termos de Aristóteles, em uma "mimese indireta". O mesmo vale para os mistérios medievais, reescritas de passagens escolhidas da Bíblia, e também o gênero dos milagres, que não é nada mais do que a adaptação para o palco de lendas de santos. O trabalho em oficina de escrita permite explorar esses fenômenos de transmodalização e observar a 
maneira com que as transformações genéricas influem na própria escrita e orientam profundamente seu sentido.

Parece igualmente proveitoso abordar a história do romance como diálogo intertextual, se considerarmos, a partir de Bakhtin, que o romance "parodia" os outros gêneros. A retomada paródica dos procedimentos próprios a um gênero conduz à renovação das formas e à invenção de um novo gênero, às vezes reconhecido enquanto tal muito tempo depois. Milan Kundera, em Os testamentos traídos (2017), sublinha o fato de que as narrativas de gigantes de Rabelais não eram percebidas como romances quando de sua publicação, mas tornaram-se romances pelo fato de que diversos romancistas passaram a nomeá-las assim de forma explícita: é este fenômeno de intertextualidade que fez de Rabelais, retrospectivamente, um dos inventores do romance europeu.

Como explorar essas questões em uma oficina de escrita? Tomemos o exemplo da narrativa das origens do gigante Pantagruel (capítulo 1), descendente de uma família que remontaria à absorção de nêsperas (mesles), frutos monstruosos produzidos pouco depois do assassinato de Abel por Caim. As referências intertextuais são múltiplas: paródia do Gênese, com a referência a Caim e Abel, depois ao dilúvio e à arca de Noé; alusão também ao início do Evangelho de Mateus, com a paródia de genealogia de Cristo. Essa genealogia fantasiosa e a relação com seus hipotextos bíblicos permitem então compreender não apenas como funciona o cômico em Rabelais, mas também como se cria o novo gênero que Rabelais inventa (que, por sua vez, se inspira em Luciano de Samósata) e o quanto isso se deve à paródia. Mas, principalmente, o fato de experimentar por si próprio a escrita paródica pode permitir que se enfrentem os desafios dessa paródia: fonte de cômico, de dessacralização de textos sagrados, na tradição carnavalesca do mundo invertido, onde tudo é permitido, até debochar das Santas Escrituras, mas também, e sem dúvida ao mesmo tempo, homenagem a esses textos e reinterpretação de seu sentido. Pode-se então buscar, através da intertextualidade, os vínculos que unem, ao longo da história, um conjunto de romances paródicos de forte dimensão crítica, de Cyrano de Bergerac a Céline, passando por Diderot e Flaubert. 


\section{Pastiche e história dos movimentos literários}

O pastiche não é apenas, como dizia Proust, uma maneira de fazer crítica literária em ato. Pode ser também um modo de ensinar a história dos movimentos literários. Se definirmos os pastiches, a partir de Gérard Genette, como imitação indireta, não de um texto específico, mas de um conjunto de textos dos quais se extraem as características, tanto as estilísticas quanto as temáticas, constatamos que não se reduzem aos pastiches de autores. Os pastiches de movimentos literários, mais numerosos do que se pensa no interior das obras literárias ${ }^{14}$, têm o grande interesse de apresentar um tipo de acúmulo de traços estilísticos e temáticos próprios a esses movimentos.

Tomemos o exemplo do próprio pastiche que Du Bellay fez do petrarquismo em seu poema "Contra os petrarquistas", poema ainda mais interessante por representar uma espécie de autopastiche: o poeta da Pléiade debocha igualmente de si próprio e de seu "período petrarquista", enumerando todas as imagens hiperbólicas e estereotipadas tiradas de Petrarca para evocar a beleza divina do ser amado e as torturas infinitas pelas quais passa este amante perfeito que é o poeta. Fazer, em uma oficina de escrita, um pastiche da escrita petrarquista, preciosa, romântica ou surrealista, exige que se tenha previamente lido um conjunto de textos, atentado para as maneiras recorrentes de escrever, para os motivos, os topoi e os gêneros de predileção próprios a esses movimentos. Tal pastiche pressupõe, em suma, ser primeiro um leitor atento à especificidade de uma escrita e à sua inscrição em um contexto histórico e cultural particular. Ao final, o fato de ter escrito à maneira dos românticos permite que posteriormente se perceba, em um texto literário não romântico, como em Flaubert ou Villiers de l'Ilse Adam, os pastiches românticos disseminados e compreender sua significação irônica.

Para todos os casos, trata-se de apreender pela experiência de escrita (e de leitura concomitante) a porção de filiação e de historicidade de qualquer produção literária.

\footnotetext{
14 Pensemos no pastiche de Montaigne em La Bruyère, nos pastiches dos preciosos em Molière ou La Fontaine, nos pastiches românticos em Flaubert, no pastiche da prosa artística dos Goncourt em Proust...
} 


\section{Reflexividade e reescrita de si: da escrita literária à escrita crítica}

Mas para se atingir o objetivo ambicioso de fazer história e teoria literárias em ato é indispensável introduzir, no interior da oficina de escrita, uma dimensão de reflexividade. Ou seja, a oficina de escrita deve colocar cada estudante em uma postura de leitor vigilante e ativo, tanto em relação a si mesmo quanto aos outros participantes. O professor tem, nessa ótica, um papel essencial a desempenhar, já que cabe inicialmente a ele reagir às leituras, dar conselhos para ir adiante, melhorar ou acentuar tal ou tal aspecto e indicar de qual maneira se pode ir além da primeira versão escrita em sala de aula.

É nessa perspectiva que um encontro é reservado, no início da oficina, aos rascunhos de escritores: ele chama a atenção sobre a importância da reescrita e da maneira de retrabalhar os escritos. Partimos da análise de manuscritos de escritores trazidos pelos estudantes, e o encontro se destina ao trabalho sobre as quatro operações principais da reescrita de si (substituição, deslocamento, amplificação e redução).

Muito rapidamente, uma vez instaurada uma regra de funcionamento essencial, a escuta generosa do grupo, uma vez superadas as primeiras angústias quanto à ideia de mostrar os textos em público, pode-se levar os estudantes a comentar os escritos dos outros. Pode ser benéfico, às vezes, designar um leitor diferente para cada texto lido, que sabe antecipadamente que deverá comentar, interrogar-se sobre a conformidade do texto com relação à atividade proposta (sabendo que é sempre possível transgredir a proposta, com a condição de se estar consciente disso) e dar sugestões de reescrita.

Essa mesma postura crítica é exigida de cada estudante em relação aos próprios escritos, no momento em que ele "passa a limpo", com mais frequência em um editor de textos, todos os textos que ele produziu, em sala de aula e fora dela. São esses comentários críticos que permitem a descoberta dos efeitos inesperados do dispositivo de escrita posto em prática.

Muitos estudantes insistem, por exemplo, no papel do grupo na orientação das segundas versões: estas, dizem eles, são frequentemente inspiradas nos textos dos outros. 
Eles ousam então ir mais longe, soltar-se mais ou, ao contrário, acentuar a dimensão cômica, transgredir mais a proposta ou, ao contrário, segui-la mais de perto. Às vezes, são as reações dos outros estudantes a sua leitura (risos, contrassensos eventuais, comentários diversos...) que os levam a reorientar, especificar ou acentuar a segunda versão. Em outras palavras, o diálogo intertextual ocorre também entre eles, no interior da oficina, e o conceito de "produtividade" assume então todo seu sentido. Muitos falam do quanto o grupo sustenta, suscita o desejo de escrever, a ponto de às vezes terem consciência de estarem escrevendo para os outros: "Durante esse curso, nós nos alimentamos uns aos outros", relata uma estudante. "A interpretação de cada um enriquece nossa leitura. Nossas criações são o fruto de um trabalho coletivo".

Entre os benefícios secundários, nota-se igualmente uma surpreendente segurança oral desenvolvida pelos estudantes, alguns dos quais confessando que hesitavam em participar da oficina basicamente pelo medo de ter que ler seus textos diante dos outros. Progressivamente, por uma espécie de emulação do grupo, esse desafio se transforma em prazer. Em lugar de serem lidos a toda velocidade, os textos são falados cada vez com mais força e convicção, compartilhados, às vezes teatralizados, e a aula destinada à escrita teatral em duplas se torna então possível.

Todos comentam sobre a qualidade humana das relações que se estabelecem no grupo, inclusive entre estudantes de idades muito diferentes. A escrita assim compartilhada permite, em apenas algumas aulas, um conhecimento do outro muito mais intenso e profundo que em dois anos de curso. Mas a escrita leva também os estudantes a descobrirem a própria escrita, a se descobrirem ou se surpreenderem consigo mesmos, a tomarem consciência de certos estereótipos, a ousarem se lançar em registros ou gêneros novos.

Enfim, o trabalho de reflexão crítica torna possível o retorno a uma escrita crítica, de alguma maneira remotivada e com maior qualidade. Certas propostas de escrita levamnos a perceber a fronteira às vezes tênue entre ficção e comentário: em uma aula dedicada à tradução, os estudantes tomam consciência, ao transporem uma página de Montaigne para o francês contemporâneo, que a tradução leva a interpretar, que a paráfrase também 
implica a interpretação e que a amplificação carrega uma parcela de invenção. E quando eles fazem uma segunda versão de Montaigne "para jovens leitores”, o ensaio toma com frequência a forma do conto ou da parábola e cai novamente na ficção. Mas, principalmente, o fato de se autorizarem a fazer um julgamento dos escritos de seus companheiros de escrita é um trampolim para poderem em seguida se autorizar a fazer um julgamento sobre obras literárias e interpretá-las, o que, sabemos bem, mesmo na universidade não é algo tão frequente. A tendência comum é de se esconder atrás das obras críticas, que são, precisamente, autoridades.

"Entre efervescência, febre e dúvida, nós adentramos no processo de criação", escreveu uma estudante em sua avaliação de fim de semestre. A experiência de escrita em oficina é, de fato, preciosa, eu ousaria dizer indispensável, para penetrar no processo de criação. Não se trata, evidentemente, de dar a ilusão a todos os estudantes de que uma carreira de escritor se abre para eles, mas de permitir que escrevam melhor, que utilizem a escrita para si mesmos, para pensar melhor, para se conhecer, para melhor compreender e apreciar a literatura.

A escrita por restrição (contrainte), por apropriação e por desvio dos textos leva a lugares onde não se cogitava ir, convida a descobrir gêneros, registros que antes pareciam estrangeiros ou impossíveis. Ela leva a lutar contra os estereótipos e a falar de si de uma maneira paradoxalmente muito mais livre. Ela permite, então, perceber a dimensão fundamentalmente oblíqua da literatura: fala-se de si mesmo tomando emprestadas a língua e as palavras dos outros, das quais tentamos nos apropriar. Ela permite, finalmente, libertar a leitura ao mesmo tempo que liberta a escrita. A observação dos estudantes me leva a concordar totalmente com esta intuição de Roland Barthes (1987, p. 36): “[...] para mim, a minha convicção profunda e constante é que nunca será possível libertar a leitura se, num mesmo movimento, não libertarmos a escrita". 


\section{ATELIER DE RÉÉCRITURE ETT CRITIQUE LITTÉRAIRE EN ACTE À L'UNIVERSITÉ}

RESUME: Traduction en portugais de l'article « Atelier de réécriture et critique littéraire en acte à l'université », de Violaine Houdart-Merot, paru dans le Journal français de psychiatrie, v. 31, n. 4, 2007. Dans ce travail, l'auteure fait un bilan de ses expériences d'animation de l'atelier « Écriture d'invention et réécriture » pour les étudiants de licence de l'Université de Cergy-Pontoise, centré sur l'étude de l'intertextualité. Outre la présentation des objectifs et du fonctionnement de l'atelier, l'auteure propose une réflexion sur les présupposés théorico-méthodologiques qui soutiennent ses pratiques et sur les potentialités de cette modalité d'enseignement de littérature via des activités de création littéraire.

MOTS-CLES: Enseignement de littérature ; Enseignement universitaire ; Intertextualité ; Atelier de création.

\section{REFERÊNCIAS}

ANDRÉ, Alain. Babel heureuse: l'atelier d'écriture au service de la création littéraire. Paris: Syros, 1989.

ARMAND, Anne. L'histoire littéraire, théories et pratiques. Toulouse: Bertrand-Lacoste; CRDP Midi-Pyrénées, 1993.

BAKHTIN, Mikhail M. Problemas da poética de Dostoiévski. 5. ed. Trad. Paulo Bezerra. Rio de Janeiro: Forense Universitária, 2013.

- A cultura popular na Idade Média e no Renascimento: o contexto de François Rabelais. 3. ed. Trad. Iara Frateschi Vieira. São Paulo: HUCITEC, 1996.

- Questões de literatura e de estética: a teoria do romance. 5. ed. São Paulo: HUCITEC; Annablume, 2002.

. Estética da criação verbal. 3. ed. São Paulo: Martins Fontes, 2000.

BARTHES, Roland. Sobre a leitura. In: BARTHES, Roland. O rumor da língua. Trad. António Gonçalves. Lisboa: Edições 70, 1987. p. 31-38.

. Texto (teoria do). In: BARTHES, Roland. Inéditos. Vol I - Teoria. Trad. Ivone

Castilho Benedetti. São Paulo: Martins Fontes, 2004. p. 261-289.

BAUCHAU, Henry. L'Écriture à l'écoute. Arles: Actes Sud, 2000.

BIASI, Pierre-Marc de. Intertextualité (théorie de). In: Encyclopaedia universalis, 1975.

BOISSINOT, Alain. Littérature et histoire. Toulouse: Bertrand-Lacoste, 1998. 
BON, François. Tous les mots sont adultes: Méthode pour l'atelier d'écriture. Paris: Fayard, 2000.

CHAR, René. Ma feuille vineuse. In: CHAR, René. Oeuvres complètes. Paris: Gallimard, 1983. p. 534.

COMPAGNON, Antoine. La seconde main ou le travail de la citation. Paris: Seuil, 1979.

O trabalho da citação. 2. ed. Trad. Cleonice P. B. Mourão. Belo Horizonte: UFMG, 2007

COSTA, Philippe. Petit manuel pour écrire des haïku. Arles: Philippe Picquier, 2000.

GENETTE, Gérard. Palimpsestes. Paris: Seuil, 1982.

. Palimpsestos: a literatura de segunda mão. Trad. Luciene Guimarães e Maria Antônia Ramos Coutinho. Belo Horizonte: Faculdade de Letras/UFMG, 2006.

HAMON, Philippe. L'Ironie littéraire: Essai sur les formes de l'écriture oblique. Paris: Hachette Supérieur, 1996.

HOUDART-MEROT, Violaine. Mise en perspective historique. Perspectives actuelles de l'enseignement du français, MEN, Direction de l'enseignement scolaire, CRDP de l'académie de Versailles, 2001.

. Un mythe et sa réécriture: la descente aux enfers. In: LANCREY-JAVAL, R. (org.). Des textes à l'oeuvre, Français 1're Paris: Hachette-Éducation, 2001. p. 362-383.

. Réécriture et écriture d'invention au lycée. Paris: Hachette-Éducation, 2004.

. Bakhtine, père ou ancêtre de l'intertextualité?. In: HAILLET, P.-P. (org.). Regards sur l'héritage de Mikhaïl Bakhtine, CRTH, Université de Cergy-Pontoise, contribution au séminaire annuel du CRTH 2002-2003, 2005a.

. Proust Dormeur éveillé, ou comment surseoir à l'arrêt de mort. In: CHAULETACHOUR, Chr. (org.). Les Mille et Une nuits dans l'imaginaire du XXe siècle. Paris: L'Harmattan (Études transnationales francophones et comparées), 2005b.

Le pastiche de genre, entre feinte et réflexivité. In: DOUSTEYSSIER-KHOZE, C.; PLACE-VERGHNES, Fl. (ed.). Poétiques de la parodie et du pastiche de 1850 à nos jours. Actes du colloque international de l'université de Durham. Berna: Peter Lang, 2006. p. 289.299.

JENNY, Laurent. A estratégia da forma. In: JENNY, Laurent et al. Intertextualidades. «Poétique» n. 27. Trad. Clara Crabbé Rocha. Coimbra: Livraria Almedina, 1979. p. 5-49.

KRISTEVA, Julia. Introdução à semanálise. Trad. Lúcia Helena França Ferraz. Sâo Paulo: Perspectiva, 1974.

KUNDERA, Milan. Os testamentos traídos. São Paulo: Companhia das Letras, 2017. 
OULIPO. La Littérature potentielle. Paris: Gallimard, 1973.

PIEGAY-GROS, Nathalie. Introduction à l'intertextualité. Paris: Dunod, 1996.

PIMET, Odile; BONIFACE, Claire. Ateliers d'écriture: mode d'emploi. Issy-les-Moulineaux: ESF, 1999.

PROUST, Marcel. A Propósito do "Estilo" de Flaubert. In: PROUST, Marcel. Nas Trilhas da Crítica. Trad. Plínio Augusto Coelho. São Paulo: Edusp ; Imaginário, 1994. p. 65-85.

RABAU, Sophie. L'Intertextualité. Paris: Flammarion, 2002.

RIFFATERRE, Michael. La syllepse intertextuelle. Poétique, n. 40, nov. 1979.

ROSSET, Clément. Le Choix des mots. Paris: Minuit, 1995.

SANGSUE, Daniel. La parodie. Paris : Hachette, 1994.

SPERGER, Dan; WILSON, Deirdre. Les ironies comme mentions. Poétique, n. 36. Paris: Seuil, 1978.

TODOROV, Tzvetan. Mikhaïl Bakbtine, le principe dialogique. Paris: Seuil, 1981.

\section{REFERÊNCIAS (artigo original)}

HOUDART-MEROT, Violaine. Atelier de réécriture et critique littéraire en acte à l'université. Journal Français de Psychiatrie, Paris, v. 31, n. 4, p. 39-43, 2007. Disponível em: https://www.cairn.info/revue-journal-francais-de-psychiatrie-2007-4-page-39.htm. Acesso em: 10 jan. 2019. 